\title{
NOTAS PARA UM VERBETE DO VOCABULÁRIO ANTONIO CANDIDO
}

\section{NOTES FOR A ENTRY OF ANTONIO CANDIDO VOCABULARY}

\author{
Francisco Roberto Papaterra Limongi Mariutti ${ }^{1}$ \\ Universidade de São Paulo - pós-doutorado ${ }^{2}$
}

\section{RESUMO}

Considera-se que em breve será organizado um Vocabulário Antonio Candido, em que conceitos postos em prática pelo autor de Formação da Literatura Brasileira sejam analisados; as presentes notas são um esboço do verbete 'Forma Literária na concepção de Antonio Candido'.

PALAVRAS-CHAVE: Antonio Candido; Forma Literária; Imaginário Crítico de Esquerda; Terminologia Crítica.

\section{ABSTRACT}

It is considered that an Antonio Candido Vocabulary will soon be organized, in wich conceptions put into practice by the author of Formação da Literatura Brasileira are analysed; the present notes are a draft of the entry 'Literary form according to Antonio Candido'.

KEYWORDS: Antonio Candido; Literary Form; Critical Imaginary Left; Critical Terminology.

\author{
À memória de Luiz Tadeu, meu irmão. \\ Minas Gerais, fruta paulista, \\ Sambre et Meuse bem marxante, \\ Periga às vezes, por confiança \\ Nas gageures. ${ }^{3}$ \\ Mário de Andrade, Lira Paulistana
}

\footnotetext{
${ }^{1}$ Doutor em Literatura Brasileira pela Universidade de São Paulo. E-mail: frplmariutti@uol.com.br

2 Agradeço a leitura de uma versão prévia destas notas por Maria Augusta Bernardes Fonseca, Vinicius Dantas e Zenir Campos Reis.

3 O trecho da epígrafe (ANDRADE, 2013, p. 393, v. I) é decifrado pelo próprio Antonio Candido em entrevista a Gilberto Velho e Yonne Leite (Museu Nacional, UFRJ): "Em Clima [revista] nós éramos quase todos praticamente apolíticos na altura de 1941 e ele [Mário de Andrade] escreveu uma carta a Paulo Duarte onde nos dava umas malhadas. Ao mesmo tempo, repito, gostava de nós, se interessava pelas nossas atividades e ali por 1943 ou 44, chegou a escrever um poema que apareceu póstumo em Lira paulistana, com uma quadra sobre cada um de nós. Elas são herméticas e pouca gente entende. Algumas, nós mesmos não entendemos. A minha é das mais claras: 'Minas Gerais, fruta paulista,/Sambre et Meuse bem marxante,/Periga às vezes, por confiança/ Nas gageures'. Ele escreveu 'marxante' com x, dando grande ambiguidade a 'marcha'. Sambre et Meuse (introduzida pela missão militar francesa na Força Pública de São Paulo e ligada afetivamente a revolução de 1932, quando servia de pano de fundo radiofônico para os comunicados de guerra), porque naquele tempo eu estava fazendo uma crítica marcada pelas posições marxistas, algumas das quais lhe pareciam trazer conclusões arriscadas (as gageures). No fundo, eu seria um mineiro mais paulista do que pensava, e para isso citou um verso dele próprio do 'Noturno de Belo Horizonte': 'Minas Gerais, fruta paulista'". Disponível em: < canalciencia.ibict.br/notaveis/livros/antonio_candido_14.html> Acesso em: 04 out. 2016
} 


\section{Um pouquinho de História}

Nada mais distante da postura mental de Antonio Candido de Mello e Souza (adiante, AC) que a ânsia de criar nomenclatura específica, supostamente rigorosa, para designar fenômenos literários e culturais. Para bendizer esse princípio de conduta, convém citar um poeta que compartilha com o crítico muitas afinidades:

Do programa epistemológico da obra,

Do corte epistemológico e do corte dialógico,

Do substrato acústico do culminador,

Dos sistemas genitivamente afins,

Libera nos, Domine.

$[\cdots]$

Das aparições de Chomsky, de Mehler, de Perchonock

De Saussure, Cassirer, Troubetzkoy, Althusser

De Zolkiewsky, Jakobson, Barthes, Derrida, Todorov

De Greimas, Fodor, Chao, Lacan et caterva

Libera nos, Domine.

(ANDRADE, 2002, p. 867) .

"Exorcismo" é um poema de Drummond dos anos 1970, época em que estudar literatura tornou-se, para muitos, oportunidade para exibir conhecimento de linguagem e autores nunca dantes mencionados; repetia-se, no campo do ensaísmo, o fetiche tecnocrata, pleno de dogmas e mantras, de que a ideologia da competência ${ }^{5}$ é um exemplo rematado. Não é à toa que o poema parodia uma reza. Enfim, a obnubilação do pensamento no campo das Ciências Humanas é o pano de fundo desse poema. Mas - a palavra adversativa ganha impulso e significado em momentos de crise e encarna a quase profecia de Hölderlin, segundo a qual é apenas do perigo que se pode esperar a salvação -, portadores de espírito verdadeiramente desassombrado optam por enfrentar o touro a unha e escrevem ensaios como "Dialética da malandragem" e "Passagem do dois ao três - De cortiço a cortiço" ", análises incontornáveis de dois romances centrais do século XIX literário nacional, e poemas cáusticos como 'Relatório de Maio', escrito no calor da

\footnotetext{
${ }^{4}$ Publicado em 1975, no Jornal do Brasil, no período de abertura à ditadura militar e em meio à vigência do estruturalismo no país, 'Exorcismo’ é um poema da coletânea intitulada sintomaticamente Discurso de primavera e outras sombras, de 1977, uma compilação de poemas em seções cujos subtítulos são igualmente sugestivos: "Notícias do Brasil", "Os marcados", "São Sebastião e pecadores do Rio de Janeiro", "Capítulos de história colonial”, "Assim vai (?) o mundo" e "Música de fundo" - o poema "Exorcismo" encontra-se nessa última.

5 Marilena Chaú, em vários trabalhos, sobretudo nos quais a universidade contemporânea é o assunto, tratou a questão com a agudeza habitual. Henri Lefebvre, em livro publicado em 1967, época em que assuntos dessa ordem só eram percebidos por pouquíssimos, teve a lucidez de se contrapor ao produtivismo que então iniciava a dominar as Ciências do Espírito; não à toa, os acontecimentos de maio de 68, não compreendidos de imediato, centravam-se também nesse ponto. Uma das caracterísiticas principais do discurso tecnocrata é subdividir os assuntos da experiência humana em partes, atribuindo legitimidade apenas aos 'especialistas' nessa ou naquela; o resultado é perder de vista o todo, do qual o Marxismo não abre mão; essa insistência em avocar a totalidade é chamada pelos tecnocratas de apego a uma visão superada. Só mesmo rindo... embora não tenha graşa alguma. (CHAUÍ, 2014); (LEFEBVRE, 1977).

${ }^{6}$ Vinicius Dantas (CANDIDO, 2002, p. 51-76), em "Duas vezes 'A passagem do dois ao três", confronta numa montagem dos textos frente a frente, duas versões relativas ao segundo título acima mencionado, cuja matriz é o ensaio "De cortiço a cortiço", publicado posteriormente. Uma, "A passagem do dois ao três (Contribuição para o estudo das mediações na análise literária)", foi publicada na Revista de História, USP, n. 100, em 1974. Outra, provinda de "A prática de interpretação de textos a partir de uma ótica interdisciplinar", conferência apresentada em 1975 no II Encontro Nacional de Professores de Literatura, no Rio de Janeiro, foi publicada em Cadernos PUC, n. 28, 1976, com o título: "Literatura - Sociologia: análise de O cortiço de Aluísio Azevedo". Os dois ensaios, "Dialética da malandragem" e "De cortiço a cortiço", foram finalmente publicados em O discurso e a cidade (CANDIDO, 1993).
} 
hora, em maio de 68, com o qual 'Exorcismo' forma um par de documentos da época, sem deixar de ser alta poesia, ou talvez por isso mesmo:

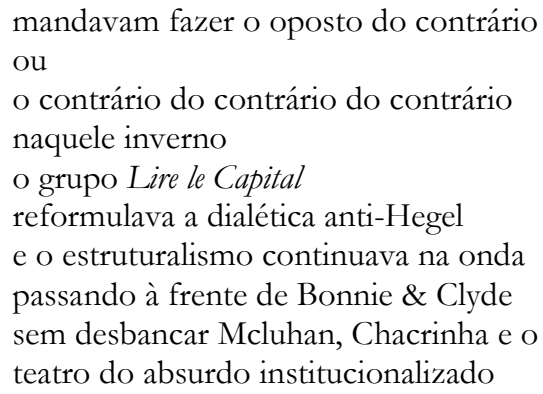

(ANDRADE, 2002, p. 1308) ${ }^{7}$.

Um crítico que dá continuidade à obra de AC, Roberto Schwarz, na mesma época e incidindo sobre o mesmo assunto, elaborou uma paródia do novo jargão fantasmagórico - 'o semantema glúteo, em linguística moderna, tende à polissemia' 8 - que ganhava espaço no mundo acadêmico, como se fosse a brilhante conclusão de uma sequência de argumentos consolidados. Tratava-se de uma entre várias sugestões - apresentadas ironicamente numa lista de princípios meio desengonçada, com número quebrado e repetições - para cair nas armadilhas de uma crítica anódina; no fim das contas, o conjunto ganhava ares de um Zeitgeist hipnótico e desconfortável.

$\mathrm{Na}$ intenção de elucidar um dado, registre-se que alguns teóricos e críticos listados nos últimos versos de 'Exorcismo' eram estudados nos cursos de AC, o que não significa que o autor de Formação da Literatura Brasileira os seguisse, ou, menos ainda, que os tomasse como modelos enquanto ensaísta; antes, considerava estar diante de um conjunto de autores cuja obra, marcos da Teoria Literária no século XX, devesse ser conhecida pelos alunos. Em várias ocasiões, afirmou que os estudos literários ganharam impulso significativo graças aos assim denominados formalistas russos e aos estruturalistas. A análise de Les chats, feita por Jakobson e Lévi-Strauss (JAKOBSON, 1974, p. 163-188), certamente o ponto máximo do Estruturalismo em matéria de leitura de poesia, era objeto de uma aula inteira de um curso sobre Baudelaire.

Nos anos 30, na USP, AC foi aluno de Lévi-Strauss, futuro autor de Antropologia estrutural. Numa passagem célebre de Tristes trópicos ${ }^{9}$, pode-se incluí-lo entre os alunos que são nomeados pelo filósofo francês, inclusão sugerida na menção à Gilda, Décio, Ruy, certamente uma referência a seus alunos Gilda de Mello e Souza, Décio de Almeida Prado e Ruy Coelho, companheiros de AC na revista Clima e também contemplados com uma estrofe para cada um na Lira paulistana, de Mário de Andrade.

Estudioso sempre atualizado, AC sempre se mostrou imune às modas intelectuais, das Ciências Humanas em suas amplitude e implicações, demonstrando, por outro lado, especial interesse pela 'ordem das ideias', ou seja, pela sistematização do pensamento a partir de princípios epistemológicos sólidos, o que resultou em muitos anos de docência no curso de Ciências Sociais e na elaboração de uma tese - um clássico sobre trabalhadores rurais em tempo de transformação dos meios de subsistência, no limite da anomia (CANDIDO, 1997). Como

\footnotetext{
7 'Relatório de Maio' foi acolhido em livro em 1985, no volume Amar se aprende amando. Ver em Poesia completa (ANDRADE, 2002, p. 1273-1361).

${ }^{8}$ Inicialmente estampado na página de abertura do n. 2 de Almanaque - Cadernos de Literatura e Ensaio (1976-1982), uma revista de cultura com forte ressonância no período, o texto de "19 princípios de crítica literária" foi publicado a seguir na coletânea de ensaios do autor, O pai de família e outros estudos (SCHWARZ, 1978).

9 "[...] essas grandes reviravoltas da história que, nos livros, parecem resultar do jogo das forças anônimas agindo no centro das trevas, também podem, num claro instante, realizar-se pela resolução viril de um punhado de crianças bem-dotadas". Claude Lévi-Strauss refere a postura de seus ex-alunos diante do desafio de equiparar a nascente universidade dos trópicos às europeias. O trecho citado é antecedido por uma mensagem cifrada, solene e irônica a um só tempo, na qual está incluso um pedido prévio de desculpas. (LÈVI-STRAUSS, 2012, p. 100).
} 
professor de Literatura, desde o final dos anos 50, aggiornato em relação à ficção, à poesia, às teorias e aos estudos que despontavam - pela soma dessas qualidades, conhecedor dos fundamentos da crítica estruturalista, portanto conhecedor do alcance dessa corrente críticoteórica, AC não a encarava como bicho-papão, o que era comum entre seus colegas de esquerda, posto que, nas universidades brasileiras, no início dos anos 70, o Estruturalismo de feição técnica e asséptica ${ }^{10}$, desconsiderava quaisquer vínculos entre os universos interno e externo da literatura, chegando ao caricato, como Drummond e Schwarz apontam. Daí, como corrente crítico-teórica adequada aos novos tempos, tomou o lugar que o Marxismo então ocupava - não é preciso lembrar aqui a longa lista de males do período: expurgo de bibliotecas públicas e particulares, editoras e jornais censurados, afastamento arbitrário de professores, Estado enquanto agente do terror, medo generalizado.

O poema de Drummond, note-se, menciona alguns nomes fantasmagóricos, como se listasse as personagens Conde Drácula, Frankenstein e Zé do Caixão - algumas aparições - em chave cômica, não como encarnação do mal à vera, que deveria ser enfrentado a qualquer custo, o que acontece, por exemplo, num combativo artigo de Carpeaux (1967). Drummond e Schwarz combatem esses seres pela ironia e pelo riso e, de maneira diversa, o autor de "O Estruturalismo é o ópio dos literatos" (CARPEAUX, 1967) procura o debate intelectual aberto, público. Não está em jogo um "Exorcismo" à obra dos citados, mas o modo, naquele tempo, início dos anos 70, como estes surgiam em muitos trabalhos de crítica literária: treslidos, citados fora de contexto e sem vínculo com a argumentação em curso, reduzidos não raro a esquemas gráficos, como se a mera menção de um nome - acompanhada de uma piscadinha que significava também en faço parte desse time - desse conta do difícil trabalho analítico. Um teórico ou um conceito puxado pelos cabelos, nesse ambiente de reificações a mancheia, passam a ser sinônimo de grife - índice claro da falência do projeto de desvendamento de que toda crítica digna do nome é portadora.

Desde os anos de formação, a trajetória intelectual de AC é paralela ao Estruturalismo e mantém com essa corrente crítico-teórica um diálogo constante, não uma identificação. Por coincidência, a extensão dos principíos estruturalistas da Antropologia e Linguística para outras áreas, inclusive a Crítica Literária, se deu em momento próximo à transferência de AC da Seção de Sociologia na USP para o curso de Letras em Assis, onde lecionou Literatura Brasileira. Primeiro, que se considere a proximidade pela atenção às mesmas questões - estrutura e forma literárias; segundo, que se registre a diferença de concepção de estrutura e forma e, por conseguinte, de literatura.

De modo sutil, AC propunha, já a partir do título dos ensaios, "Passagem do dois ao três" e "Dialética da malandragem", leituras em que o esquema binário típico de certo Estruturalismo - o de Greimas, por exemplo, talvez o mais refratário às motivações histórico-sociais da literatura - é superado, no sentido hegeliano de Aufhebung.

As palavras de Roberto Schwarz,

Antonio Candido - que é da mesma geração do Goldmann - desenvolveu um tipo de estruturalismo histórico para responder pela esquerda ao estruturalismo anti-histórico que se havia formado nas ciências sociais e na crítica literária. Imagino que a semelhança se deva a esse contexto teórico-político em comum, e não à influência. Não custa lembrar que o melhor do pensamento crítico da esquerda brasileira depende de alguma forma de estruturalismo histórico. Basta pensar em Caio Prado Jr. e Celso Furtado. (SCHWARZ, 2000, p. 62).

confirmam as de AC:

\footnotetext{
10 Talvez não seja inoportuno lembrar que o Estruturalismo na França teve um sentido contestador e contrário às mistificações literárias, conforme François Dosse (1993), estudioso do assunto; o que ocorreu nas universidades brasileiras, o exato oposto, é um fenômeno em que se cruzam a vida intelectual vergada por forças políticas e a sensação quase plena e plenamente barroca de mundo às avessas, vivida por tantos no transe 60-70.
} 
[...] uma característica do enfoque estrutural é não apenas concentrar-se na obra tomada em si mesma (o que aliás ocorria em outras orientações teóricas anteriores), mas relacioná-la a um modelo virtual abstrato, que seria a última instância heurística. (CANDIDO, 2002, p. 78).

[...] O enfoque estrutural (inclusive sob a modalidade mais recente, conhecida como estruturalismo) é responsável pelo maior avanço que os estudos literários conheceram em nosso tempo. Mas vai ficando cada dia mais claro que uma visão íntegra da literatura chegará a conciliar num todo explicativo coerente a noção de estrutura e a de função, que aliás andaram curiosamente misturadas e mesmo semanticamente confundidas em certos momentos da Antropologia inglesa dos anos de 1930 e 1940 . E nós sabemos que a Antropologia é, com a Lingüística, uma das grandes fontes do estruturalismo contemporâneo. (CANDIDO, 2002, p. 79).

[...] na medida em que nos interessa também como experiência humana, não apenas como produção de obras consideradas projeções, ou melhor, transformações de modelos profundos, a literatura desperta inevitavelmente o interesse pelos elementos contextuais. Tanto quanto a estrutura, eles nos dizem de perto, porque somos levados a eles pela preocupação com a nossa identidade e o nosso destino, sem contar que a inteligência da estrutura depende em grande parte de se saber como o texto se forma a partir do contexto, até constituir uma independência dependente (se for permitido o jogo de palavras). Mesmo que isto nos afaste de uma visão científica, é difícil pôr de lado os problemas individuais e sociais que dão lastro às obras e as amarram ao mundo onde vivemos. (CANDIDO, 2002, p. 79).

A questão decisiva é a distância entre o modelo virtual abstrato, o ponto de chegada dos estruturalistas, e a concretude das especificidades históricas, como a fluidez social do malandro ou a degradação do trabalho, entre a escravidão e o mercado livre, pontos de partida de AC nas análises de Memórias de um sargento de milícias e $O$ cortiço. Grosso modo, o específico histórico são os fatores externos que moldam a estrutura das narrativas e, assim, tornam-se internos.

\section{Forma da História, Forma Literária, Formação da Literatura Brasileira}

Nos ensaios de AC acima citados, uma concepção dinâmica de forma literária, nada redutora ou dogmática, questão central da Crítica Literária, pulsa sob a escrita límpida e avessa a malabarismos retóricos. Se o ensaísta em questão prima pela clareza, haverá algo ainda por esclarecer? Suponhamos um manual de Sociologia: quantas definições de liberdade, nos universos político ou econômico, por exemplo, o livrinho terá que abranger? Todos economistas liberais têm o mesmo ponto de vista quanto a essa definição? Ou, dito de outra maneira, que se perscrute o mesmo assunto, como a historicidade da literatura, nos ensaios e estudos de alguns contemporâneos como Terry Eagleton, Dolf Oehler e Davi Arrigucci: ainda que se aproximem em vários pontos, as divergências certamente serão muitas. Assim, é esse o verbete em pauta aqui: forma literária, segundo AC.

Ainda: estas notas são como rascunho; trata-se de apenas apontar algumas das implicações de um conceito que só existe enquanto prática analítica - como prática de leitura, como se queira -, a dialética dos fatores externos e internos; ou, noutros termos, como o Mundo transforma-se em Literatura. É uma questão muito grande, vívida, envolve o sentido mesmo de ler e escrever - reduzir isso a uma fórmula, uma tentação sempre à espreita, resulta em desfigurar por completo o ponto de vista de AC. O pontapé inicial é a identificação de afinidades entre o Marxismo e a obra de AC, a partir de pontos nevrálgicos: a) a atividade crítica enquanto busca de totalidade da obra literária, o que implica uma necessária dialética entre forma e conteúdo; b) a noção de sistema, em que as partes se relacionam segundo certas orientações - pretende-se aqui indicar quais.

Hegel considera que o Estado Moderno ou Estado-Nação, cujos exemplos perfeitos seriam França e Inglaterra desde o início da Era Moderna, é uma forma histórica, portanto passível 
de transformação, passível de assumir outras formas. A análise de Marx, no início de O Capital, da forma-mercadoria tornou-se clássica, no sentido de reprodutível, ou seja, os fundamentos da análise têm a amplitude necessária para fazê-la incidir em outros objetos.

Nesse campo, o termo aqui em pauta remete à forma equivalente de valor, forma de valor simples, relativa etc. - antecedidas das motivações de Marx para instituir o termo: forma de quê, em relação a quê? Tudo é posto em relação e considerado desde a ossatura que atravessa transformações históricas. Natureza-morta e romance são formas artísticas também tornadas clássicas porque corresponderam - que se atente ao significado etimológico desse verbo: ter a mesma proporção - a experiências decisivas, cristalizadas, como a ascensão da burguesia ao poder ou a urbanização das sociedades modernas percebida como uma decadência humana, daí a idealização da vida campestre, supostamente simples e autêntica se apartada da urbe degenerada. Uma coisa é a fruta cuja árvore existe no meio da floresta, outra a que é produzida em função do mercado, a que é atribuído um valor monetário.

Com esses dados à mão, pode-se considerar que forma, na tradição hegeliana-marxista, se define como constructo, artifício, aquilo que se descola do estado de natureza ou que muda de patamar; nesse sentido, portador de uma história interna, pois o processo se desdobra, e de um significado histórico - a História por princípio, a passagem do natural ao cultivado, contígua à passagem do impulso ficcional ou poético à literatura: a centelha caótica inicial se torna inteligível porque formalizada - o mecanismo é o mesmo, os valores envolvidos, não.

$\mathrm{Na}$ perspectiva dialética, tal mecanismo é considerado em sua amplitude: a forma não apaga o caos, a não-forma, mas o torna visível, palpável, perceptível - ou seja, mantido, mas não no mesmo plano inicial - se não for um abuso de palavras de gênese comum, talvez se possa dizer plano amorfo. Idas e vindas abruptas entre a totalidade e a parte, quando está presente alguma coisa do tamanho da literatura, necessitam de lentes multifocais para ser percebidas sem distorção: forma literária e formações sociais como assuntos mais evidentes; a História de ambos como elo.

O conjunto e o específico em constante mobilidade - pontos de partida e de fuga necessários, se a totalidade ${ }^{11}$, que só está ao alcance de quem recorre à História e a hipóteses historiográficas, está em jogo. Não é por outra razão que foram historiadores, ou intelectuais guiados por hipóteses historiográficas bem fundamentadas, que melhor perceberam o sentido profundo da forma artística - Sérgio Buarque de Holanda, enquanto estudioso da literatura colonial, e Ernst Gombrich e Heinrich Wölfflin, como historiadores das artes plásticas, exemplificam à risca, em grau muito alto, o que aqui se tenta indicar. E, claro, AC, em cuja obra fundamental, Formação da Literatura Brasileira, forma e história são os polos de uma dialética viva: um estudo dos traços que vinculam árcades a românticos, sobretudo as imagens de uma sociedade periférica imperfeita, cujo conjunto perfaz uma pré-história literária. Ou melhor, a bistória dos brasileiros no seu desejo de ter uma literatura.

AC, de modo semelhante à leitura que Machado de Assis fez da tradição ficcional romântica, apontada em trecho célebre da Formação, reconfigurou a história literária brasileira, sobretudo as obras de Veríssimo, Sílvio Romero e Joaquim Norberto, releu todo o corpus dos séculos XVIII e XIX que estivesse à mão, com olhos ao mesmo tempo livres, segundo Oswald de Andrade e os modernistas, e experientes, segundo os conhecimentos universitários contemporâneos e as obras clássicas de Caio Prado Jr. e Sérgio Buarque, seus antecessores como intérpretes da nação. Ler a Formação resulta em conhecimento de história social, de literatura e de história literária, porque AC tratou de seus assuntos com a consciência de um historiador, que

11 O todo literário é um, o histórico-social, outro; ainda que sejam correlatos, mas não sinônimos. A análise de Marx aponta que o capital ao mesmo tempo organiza e desorganiza a sociedade de classes, que se mantêm em permanente tensão. O conjunto das classes é a totalidade; uma não existe sem a outra, ou ainda, uma existe em função da outra forma-se, então, uma estrutura. Illusions perdues, leitura recorrente de AC, é um romance cuja forma representa o duplo sentido do capital, e assim aponta para o todo. 
não perde de vista as transformações sofridas por seu objeto, nem as transformações das perspectivas pelas quais o objeto é estudado.

Também quanto aos ensaios, pode ser dito que a leitura resulta no conhecimento em várias áreas - literatura, história, sociologia. Para elaborar "Dialética da Malandragem" e "De cortiço a cortiço", passou a limpo a bibliografia sobre o século XIX nacional, já conhecido desde a Formação, para tomar pé dos universos a que se referem os romances em pauta; ou, dito de outra maneira, para voltar o olhar aos fatores externos que se tornaram internos.

É da mesma época a redação de Do Império à República, de Sérgio Buarque de Holanda, a obra mais abrangente sobre o período, absolutamente incontornável. Antes de publicá-la, o autor de Raizes do Brasil pediu que AC lesse os manuscritos, o que resultou em algumas sugestões e na exposição de um ponto de vista a respeito de Pedro II e dos monarquistas que não correspondia à visão de Sérgio Buarque; a partir de então, este não perdia oportunidade de se referir a $\mathrm{AC}$ como o monarquista Antonio Candido, em tom de blague, claro, pois conhecia como ninguém as convicções republicanas de esquerda do amigo. A anedota serve para registrar a alta conta em que o historiador máximo tinha $\mathrm{AC}$, não apenas como conhecedor de literatura, mas como interlocutor em matéria historiográfica. AC tornou-se um grande crítico literário porque não é apenas um crítico ${ }^{12}$.

Em 1954, quando AC apresentou Os parceiros do Rio Bonito como tese de doutorado na seção de Ciências Sociais da USP, Roger Bastide, um dos arguidores, não atribuiu nota máxima ao trabalho por considerar que não se definia como estudo sociológico ou antropológico; um problema, segundo o mestre de quase toda geração Clima, provavelmente orientado por uma exigência da mentalidade de época.

Passados alguns anos, como contraponto da especialização desmedida que tomou de assalto a universidade, os múltiplos pontos de vista recebem o nome de interdisciplinaridade e tornam-se uma solução. E se não forem impostos ou vistos como panaceia de todos os males da vida acadêmica, são um caminho bem-vindo e possível via de acesso à totalidade. Ora, nesse estudo há uma espécie de desdobramento de perspectivas em função dos desdobramentos do objeto, que recobre um arco que principia com a música e a dança caipiras e chega à economia e aos meios de subsistência, além de passar pelas formas de sociabilidade e organização dos núcleos isolados - como tratar de tudo isso tendo à mão apenas as teorias de Durkheim ou de Malinowski?

Mobilizar saberes vários foi o que fez o jovem professor e o resultado é a obra clássica, ainda que difícil de classificar, posta na fronteira das disciplinas das Ciências Humanas, aguda e atual como nunca - não é demais lembrar que a proposta de Reforma Agrária é uma de suas conclusões, uma espécie de último capítulo, posterior ao fim do livro, na qual ecoa, mesmo que não citada, a tese de Marx, segundo a qual aos filósofos não basta interpretar o mundo de diversas maneiras, cumpre modificá-lo ${ }^{13}$. A única citação de Marx em Os parceiros, a respeito da divisão entre campo e cidade, vem logo a seguir de uma menção ao conceito de bens incompressivveis, segundo o Padre Louis-Joseph Lebret:

Não são apenas os que se reputam essenciais à estrita sobrevivência do indivíduo, mas todos aqueles que permitem ao homem tornar-se verdadeiramente humano. Sob este

\footnotetext{
$12 \mathrm{O}$ alcance desses dois ensaios pode ser percebido pela leitura de ambos, em conjunto com os romances Memórias de um sargento de milícias e $O$ cortiço, acompanhados de estudos clássicos sobre a escravidão e o trabalho livre no século XIX, como os de Joaquim Nabuco, antes um libelo, Maria Sylvia de Carvalho Franco e Katia de Queirós Mattoso. Noutra chave, são muito elucidativos os seguintes estudos específicos de Roberto Schwarz: "Pressupostos, salvo engano, de 'Dialética da Malandragem"” (SCHWARZ,1987, p. 129-155) e “Adequação nacional e originalidade crítica" (SCHWARZ, 1999, p. 24-45).

${ }^{13}$ Nem AC nem ninguém desconhece que Reforma Agrária não tem nada de revolução proletária; ocorre que, diante da mentalidade de casta das oligarquias nativas, qualquer alteração na estrutura fundiária soa como uma Queda da Bastilha, vide as reações diante da proposta de Reformas de Base (agrária e urbana) anunciada por Jango Goulart em meados de março de 1964, em comício na estação de trem Central do Brasil, no Rio de Janeiro.
} 
ponto de vista, são incompressíveis a participação na beleza, a euforia da recreação, o prazer dos supérfluos. (CANDIDO, 1997, p. 226). ${ }^{14}$

Esse mesmo conceito consta de um ensaio posterior, "O direito à literatura", muito citado, em que a própria literatura, desde que tomada de uma perspectiva que não corresponde ao senso comum, é considerada como um desses bens. Talvez seja o escrito de AC em que a posição estética do autor, centrada na concepção de forma sobre a qual aqui se procura refletir, esteja mais exposta:

\begin{abstract}
A literatura confirma e nega, propõe e denuncia, apoia e combate, fornecendo a possibilidade de vivermos dialeticamente os problemas. Por isso é indispensável tanto a literatura sancionada quanto a proscrita; a que os poderes sugerem e a que nasce dos movimentos de negação do estado de coisas predominante. [...] (CANDIDO, 2011, p. 177-178).
\end{abstract}

Toda obra literária é antes de mais nada uma espécie de objeto construído; e é grande o poder humanizador dessa construção, enquanto construção.

De fato, quando elaboram uma estrutura, o poeta ou o narrador nos propõem um modelo de coerência, gerado pela força da palavra organizada. Se fosse possível abstrair o sentido e pensar nas palavras como tijolos de uma construção, eu diria que esses tijolos representam um modo de organizar a matéria, e que enquanto organização eles exercem papel ordenador sobre a nossa mente. Quer percebamos claramente ou não, o caráter de coisa organizada da obra literária torna-se um fator que nos deixa mais capazes de ordenar a nossa própria mente e sentimentos; em consequência, mais capazes de organizar a visão que temos do mundo. (CANDIDO, 2011, p. 179).

Considerar que o decisivo da literatura se encontra na forma não significa tomar a literatura como um ente fechado em si; pelo contrário, para AC, a literatura não se explica apenas nos seus próprios limites, nem apenas fora desses limites, mas na dialética entre universos interno e externo, o que descarta de imediato uma concepção de forma e linguagem literária enquanto conjunto matemático autossuficiente, dissociado da totalidade da obra, conforme preconizam algumas correntes de estudos críticos e linguísticos.

AC sempre foi avesso a rótulos, quer colados aos autores de que tratou, quer quanto a si mesmo. Porém, alguns termos que significam posturas e valores devem ser sublinhados: anticapitalista e defensor de um socialismo democrático, daí as muitas afinidades com o Marxismo; deste, procurou reter mais o espírito e o mínimo possível o jargão, parente próximo dos rótulos mencionados. Assim, é raro que a terminologia criada por Marx e pelos estudiosos do autor de $O$ capital conste dos escritos de AC; em contrapartida, neles há, de modo substancial, se é possível dizer dessa maneira, um imaginário de esquerda, próximo às especulações e estudos que tomam o Marxismo como, ao mesmo tempo, um terreno rigoroso de conceitos complexos e um campo a ser cultivado; numa palavra, um sistema que tem no horizonte a totalidade do Humano enquanto devir aberto, não enquanto resultado de uma receita pronta e acabada, o que suporia o conhecimento prévio, teleológico do futuro.

De modo semelhante, não faz sentido supor que o crítico literário seja o elo de uma suposta cadeia produtiva intelectual que se apresenta - ou deveria se apresentar - como quem comanda tal cadeia, predeterminando o papel deste ou daquele outro elo. Para AC, a Literatura,

14 Sempre é bom lembrar que na década de 50 colocar lado-a-lado Marx e um sacerdote católico era motivo de escândalo. Padre Lebret, o dominicano criador do movimento Economia e Humanismo, que teve grande repercusssão no Brasil, sobretudo na ala da Igreja que adotou a Teologia da Libertação, foi um dos redatores das encíclicas Gaudium et Spes e Populorum Progressio, ambas dos anos 60, que são uma espécie de relatório do Concílio Vaticano II, no qual Lebret teve corajosa atuação, enfrentando a ala da Igreja cega aos problemas seculares. Um ótimo exercício é ter à mão esses documentos papais, abstrair o fundamento teológico, e ler em conjunto a poesia de Drummond (ANDRADE, 2002), sobretudo Rosa do Povo em diante, e o ensaio "Inquietudes na poesia de Drummond", de AC, 1965, que consta de Vários escritos (CANDIDO, 2011, p. 69-99) - as afinidades e os pontos de contato são espantosos. Os espíritos mais agudos de um período sempre se cruzam, ainda que caminhem por trilhas diversas.

Revista do GELNE, Natal/RN, Vol. 20 - Número 1: p. 206-216. 2018 
uma atividade sem sossego ${ }^{15}$, é, não um conjunto de elos interligados que necessitem de uma mão sapiente para fazê-los circular, mas um organismo-sistema capaz de responder a estímulos dos mais variados tipos, em constante, e, não raro, tenso diálogo com a sociedade, com as instituições, com as posturas mentais estagnadas; numa palavra, uma práxis coletiva. Posto a jusante desse processo, o crítico pode situá-lo quanto à história social, à história das formas artísticas, às tradições culturais.

Avançando um pouco mais: o conjunto de estudos e ensaios de AC se entroncam numa tradição que tem $O$ capital como pano de fundo, engloba tanto a Crítica à economia política quanto a Estética de Hegel e as especulações de Marx sobre tragédia grega e Balzac, transita por marcos do século XX como Mimesis, de Auerbach, escritos de Gramsci e Trotski sobre literatura e revolução proletária, os ensaios de Benjamin sobre Baudelaire e Paris, os estudos de Henri Lefèbvre sobre o significado das monstruosidades contemporâneas a que atribuem o nome de megalópoles.

Malgrado as restrições que AC fazia ao autor de $A$ teoria do romance, sobretudo no que diz respeito à relação pouco mediada e matizada entre literatura e sociedade, também Lukács tem aí um lugar significativo; a disposição e o modo de procurar o sentido oculto que subjaz ao discurso e à camada superficial dos eventos é resultado de leitura atenta de $A$ ideologia alemã e $O 18$ Brumário de Luís Bonaparte, duas obras em que a Forma da História - com a substantiva maiúscula germânica - é questão central; certamente há outros filósofos e historiadores implicados, como Lucien Febvre, cuja obra sobre Rabelais foi lida com particular interesse ${ }^{16}$.

AC sabia mais do que ninguém, porque os leu muitíssimo bem, que os críticos, filósofos e historiadores citados acima divergiam em vários assuntos, notadamente quanto à posição da Cultura na sociedade; pela mesma razão, conhecia as convergências, que ganham o primeiro plano e, no entendimento de AC, que sempre procurou uma sistematização epistemológica do terreno em que pisava, Marx e os Marxismos tornam-se amálgama de muitas vertentes ordenadas, entre as quais a filologia alemã e a École des Annales, para citar fomas intelectuais com os quais AC dialoga e que, ao menos na origem, percorreram trilhas distantes das correntes marxistas.

A tradição do ensaio, que remonta a Montaigne e aos humanistas do século XVI, que não recua diante de assunto algum, é central na obra de $\mathrm{AC}$, o que não quer dizer que o Humanismo do autor de Tese e antitese possa ser resumido ao domínio das obras de Erasmo, Thomas Morus e outros escritores do período, ou à mera postura diante de gêneros literários. Antes uma perspectiva que um acúmulo de referências bibliográficas, o Humanismo de AC é um conjunto de amplas articulações, que vão da defesa dos Direitos Humanos - termo de longa história cujos marcos decisivos são as declarações de 1789 e 1948 - à proposição da Cultura, enquanto instância humanizadora, e do Socialismo ${ }^{17}$, enquanto princípio de organização igualitário, o que significa a partilha dos bens naturais ou os resultantes do esforço humano, quaisquer que sejam -

15 A frase abre o ensaio "Timidez do romance": "A literatura é uma atividade sem sossego. Não só os "homens práticos', mas os pensadores e moralistas questionam sem parar a sua validade, concluindo com frequência e pelos motivos mais variados que não se justifica: porque afasta de tarefas 'sérias', porque perturba a paz da alma, porque corrompe os costumes, porque cria maus hábitos de devaneio”. (CANDIDO, 1987, p. 82).

${ }^{16}$ Respondendo a uma pergunta minha a respeito de Febvre, AC mencionou a importância do estudo Le problème de l'incroyance au XVTe siècle: la religion de Rabelais, no qual encontra afinidades com a obra de Lucien Goldmann sobre Pascal, Le Dieu caché.

${ }^{17}$ Filiar-se a partidos e grupos de esquerda que propunham alternativas socialistas ou que combateram ditaduras variadas, instituídas pelo Estado Novo ou pelo golpe de 1964, faz parte de uma intensidade de espírito, em que as dimensões intelectuais, éticas e políticas se fundem; o mesmo espírito se fez presente num evento na USP, em 1998, quando AC foi homenageado por seus oitenta anos; agradeceu os elogios dos oradores que o precederam, todos referindo a alta contribuição como professor de Ciências Sociais e Teoria Literária, como sociólogo e crítico; no entanto, fez questão de sublinhar o que deixou de fazer e, citando Condorcet e São Vicente de Paulo, apontou o que estava diante de todos no Auditório da História: a universidade e a educação em crise e, mais além, os descaminhos de uma s ociedade iníqua, que a comunidade acadêmica ali presente não teria enfrentado de modo pleno. Era um jeito delicado de desfazer o oba-oba celebratório e afirmar que, em certas matérias, as providências de ordem coletiva são de tal maneira prementes, que o cuidado do indivíduo é melhor que seja posto entre parênteses. Antonio Candido, 'Discurso de agradecimento' (AGUIAR, 1999, p. 96-99). 
um grande cesto onde cabem os meios de produção, entre os quais robôs, capazes de fazer outras máquinas, e inclui conquistas como a apreciação bem informada da pintura impressionista e os procedimentos médicos mais complexos, além de vinho do Porto e música popular brasileira.

Tudo isso compõe um ponto de vista tão rico e justo a respeito da Literatura e do sujeito histórico, tanto o indivíduo quanto o coletivo, que nós, contemporâneos de $\mathrm{AC}$, ainda não somos capazes de avaliar a obra que daí resulta. E ela está diante de nós, a nos questionar - atividade sem sossego, com todas as letras - e a nos inspirar para a reflexão, para criar e agir. Foi toda construída a contrapelo dos discursos da oligarquia, que nunca deixou de dar as cartas desde o Império, das estreitezas e mesquinharias do mundo acadêmico e da burocracia untuosa dos círculos bempensantes, sempre disposta a cortar as asas da imaginação e da independência.

\section{Outros termos, outros verbetes}

AC escreveu seus estudos e ensaios num registro coloquial culto, marca de toda geração Clima, que, diante da necessidade de termo teórico inusual, lança mão de uma nota de rodapé ou de uma explicação no corpo do escrito - em termos civilizados, isto é, livre de jargão. Ao invés de anunciar o programa epistemológico da obra, AC considera que a Literatura também é uma forma de conhecimento e sem alarde, quase em surdina, direciona o ensaio a fazer ver essa dimensão relevante da ficção e da fantasia. Formação e outros estudos e ensaios são, em boa parte, fundamentados nesse parâmetro de conduta crítica, por sua vez projeção de valores estéticos de que o ensaísta é portador.

Um termo cunhado por $\mathrm{AC}$, não como resultado de especulação teórica abstratizante, mas por necessidade intrínseca à leitura de uma obra inovadora - Grande sertão: veredas - é 'supraregionalismo'. Aí já se trata de outro verbete do Vocabulário, que deve vir na sequência de 'sistema literário', proposto para compreender uma formação cultural tardia num país periférico. Noutras palavras, quando o objeto de estudo requer, e somente assim, como resposta a uma exigência legítima, real, verdadeira, formula-se e nomeia-se um conceito. É nesse sentido que pode ou deve ser entendida a paixão do concreto, expressão de Gilda de Mello e Souza, outro traço marcante da geração Clima; aliás, faz sentido que no Vocabulário haja um verbete que refira essa paixão.

\section{REFERÊNCIAS BIBLIOGRÁFICAS}

AGUIAR, Flávio (org.). Antonio Candido / Pensamento e militância. São Paulo: Humanitas; Fundação Perseu Abramo, 1999.

ANDRADE, Carlos Drummond de. Poesia completa. Rio de Janeiro: Nova Aguilar, 2002.

ANDRADE, Mário. Poesias completas. Edição de texto apurado, anotada e acrescida de documentos por Tatiana Longo Figueiredo e Telê Ancona Lopez. Rio de Janeiro: Nova Fronteira, 2013. 2 v.

AUERBACH, Erich. Mimesis. La representación de la realidad en la literatura occidental. Trad. de Ignacio Villanueva y Eugenio Ímaz. Mexico: Fondo de Cultura Económica, 1995.

CANDIDO, Antonio. A educação pela noite. São Paulo: Ática, 1987.

Entrevista a Gilberto Velho e Yonne Leite (Museu Nacional, UFRJ). Edição de texto de Dora Rocha. Colaboração Eunice Personini. Publicada em junho de 1993. Canal Ciência. Portal de Divulgação Científica e Tecnológica. Instituto Brasileiro de Informação em Ciência e 
Tecnologia (IBICT). Disponível em: < canalciencia .ibict.br / notaveis/livros/ antonio_candido_ 14.html >. Acesso em: 04 out. 2016.

. O discurso e a cidade. São Paulo: Duas Cidades, 1993.

. Os parceiros do Rio Bonito. 8. ed. São Paulo: Ed. 34, 1997.

. Tese e antítese. 6. ed. Rio de Janeiro: Ouro sobre Azul, 2006.

.Textos de intervenção. Seleção, apresentação e notas de Vinicius Dantas. São Paulo: Duas Cidades; Ed. 34, 2002. (Espírito Crítico).

. Vários escritos. 5. ed., corrigida pelo autor. Rio de Janeiro: Ouro sobre Azul, 2011.

CHAUÍ, Marilena. A ideologia da competência. Belo Horizonte: Autêntica; São Paulo: Perseu Abramo, 2014.

DOSSE, François. História do estruturalismo. Trad. de Álvaro Cabral. Campinas: Editora da Unicamp, 1993.

FEBVRE, Lucien. Le problème de l'incroyance an XVIe siècle. La religion de Rabelais. Édition revue. Paris: Albin Michel, 1947. (Bibliothèque de synthèse historique.L'évolution de l'humanité, 53).

GOLDMANN, Lucien. Le Dieu caché. Étude sur la vision tragique dans les Pensées de Pascal et dans le théâtre de Racine. Paris: Gallimard,1976.

JAKOBSON, Roman. Huit questions de poétique. Paris: Seuil, 1974.

LEFEBVRE, Henri. Vers le cybernanthrope / contre les technocrates. Paris: Denoël-Gonthier, 1971.

LÉVI-STRAUSS, Claude. Tristes trópicos . Trad. Rosa Freire D’Aguiar. São Paulo: Companhia das Letras, 2012.

LUKÁCS, Georg. A teoria do romance. Um ensaio histórico-filosófico sobre as formas da grande épica. Trad., posfácio e notas de José Marcos Mariani de Macedo. São Paulo: Duas Cidades; Ed. 34, 2000.

SCHWARZ, Roberto. Adequação nacional e originalidade crítica. In: Sequências brasileiras. São Paulo: Companhia das Letras, 1999.

. O pai de família e outros estudos. Rio de Janeiro: Paz e Terra, 1978.

. Pressupostos, salvo engano, de 'Dialética da Malandragem'. In: Que horas são? São Paulo: Companhia das Letras, 1987.

Tira-dúvidas com Roberto Schwarz. Entrevista a Afonso Fávero, Airton Paschoa, Francisco Mariutti, Marcos Falleiros. Novos estudos Cebrap, n. 58. São Paulo, novembro de 2000. p. 53-71. 